\title{
Guest Editorial: Mediations of Power in Contemporary Medical Anthropology
}

\section{Paul Brodwin}

The articles in this special issue tackle a problem at the heart of medical anthropology today - a problem that bedevils our methods, theoretical ambitions and public stance in the world. How should we rank the relative importance of local cultural meanings, on the one hand, and large-scale political and economic forces, on the other? That is, how should we train our sights on both culture and politics as we study the social contexts of suffering and apply our expertise to the worlds of policymaking and service delivery? How do we keep 'culture' and 'politics' in motion (and both are very broad analytical terms) without lapsing into one-sided analyses that champion the one term at the expense of the other? The following articles significantly advance the debate about such issues. They offer powerful theoretical models of the dialectic between culture-specific illness idioms and the operations of power that constrain people's lives. They also re-think the very notion of culture in light of the complex networks-connecting individuals to nationstates, empires, NGOs, pharmaceutical firms and global capital-in which medical anthropologists increasingly work.

As Raymond Massé notes in his contribution, a one-sided political-economy approach has recently come to dominate all other voices in medical anthropology. The paradigm of structural violence and the production of health inequalities is unquestionably an important analytic tool. It establishes a strong research agenda; it guides desperately needed clinical and public health interventions; and it carries the voice of anthropologists to the highest levels of policymaking. Unfortunately, some mistakenly conclude that the very fact of systemic inequality makes irrelevant any sustained scholarly concern with face-to-face social life and the intimate understandings of the body, selfhood and morality. Emphasizing macro-politics demonstrates how global structures of power unjustly place the burden of morbidity and morality on to the world's poor. Yet, according to some writers, the structures of power are so oppressive that anthropological interest in the full social context of illness and healing is a waste of time. In particular, the local frameworks of meaning and short-term logics through which people respond to illness seem merely exotic and a distraction to the hard questions of poverty and unequal access to health care.

The rhetoric recalls an earlier debate in anthropology, summarized succinctly by Sherry Ortner (1984). Ortner criticized the then-dominant models of political economy originally produced by Emmanuel Wallerstein and Andre Gunder Frank in the following terms: political economists of the 1970s were interested in the historical development of peasant societies. They claimed that peasants' lives were largely determined by external forces, particularly the state and the capitalist world system. Everything studied about peasant societies, in this model, had already been fundamentally transformed by forces emanating from far above the everyday context of their lives. History, for 
these political-economy writers, arrives like a juggernaut from outside the society in question. It renders moot all pre-existing cultural discourses and social relations.

Ortner found this approach to be much too thin. She argued that it cannot capture the interaction between structure and agency: that is, the manœuvres and practical understandings in which local meanings and large-scale relations of domination meet and transform each other over time. History simply does not operate in the unidirectional, top-down fashion envisioned by these mid-twentieth century political economy theorists. Full historical understanding, therefore, requires ethnographic vision, and it inevitably suffers when politics overshadows culture in scholar's toolkit. Ortner made a similar point when tracing the fate of Clifford Geertz's intellectual project (Ortner, 1999). Ever since the 1980s, the semiotic notion of culture has come in for severe criticism in part because Geertz himself set up a strong ontological contrast between issues of meaning and issues of power. For Geertz, issues of meaning subsume human creativity and the ability to make the experience of limitation and loss in social life coherent. Issues of power refer to relationships of domination, control and strategies of legitimation. Geertz championed the former as the proper subject for ethnography and cultural analysis, while disdaining the latter as fit only for reductionist, ideologically-driven approaches that ignored cultural context.

His critics retained the opposition, but reversed the emphasis. Power and domination have become central to social theory. By common consent, they are the prime movers of today's most important social trends, including globalization, post-colonial formations, imperialism, strategies of resistance, etc. From this angle, 'local knowledge' contains only a commentary upon (and at worst, a mystification of) the force-field of power and domination. Again, Ortner is not satisfied with the dismissal of meaning and intention. Cultures do, indeed, operate along the fault-lines of power, but people conceive of power and exert their agency in culturally distinctive ways. Even if the anthropologist's primary task is to decode and expose the workings of power, an anthropologist must learn about people's desires and intentions as they appear in the everyday routines, cultural idioms and the local contexts of practical action.

Holding together the analysis of both culture and power, even as it continually threatens to burst apart, is the key task for both medical anthropology and the discipline as a whole. The following papers suggest how to do it well and what dangers to avoid. Raymond Massé explores how the power imbalance between metropolitan France and its department (the former colony) of Martinique creates a collective crisis of identity. The political fact of dependency produces a shared self-perception of weakness and uselessness. That shared selfperception affects individual subjectivity. The outcome is a higher level of psychopathology: higher rates of suicide, anxiety disorders and substance use. In the end, structural inequality does produce sickness, but through several mediating steps. Massé essentially offers a threepart model in response to the challenge of linking large-scale structures of inequality to the subjective experience of distress. He proposes a mediating term: the mid-range social reality that is manifestly produced by overarching political and economic forces, but one that also surrounds the individual and that tangibly constrains daily life. In the case of Martinique, the large-scale forces include political subordination and economic dependency. The mid-range social realities include, inter alia, latent racial tension, underemployment, parental distress when children leave for better lives in France, and the rejection experienced by returning migrants. Finally, at the level of subjective experience and self-regard, Martinicans express their suffering through local concepts of social pathogenesis (sorcery, bad luck and the malign intentions of people in one's immediate social world). 
Massé finds a way out of the false dichotomy between culture and power by elaborating this mid-range realm of sociological phenomena produced by macro-level forces but directly impinging on the individual's immediate concerns. The model is convincing even if no-one in Martinique can articulate all the levels by himself/herself. The Martinican who attributes his suffering to a malign influence emanating from his social network is responding to global forces in an all-too-human way; that is, in terms of immediate personal stakes and in a language that his neighbours (and perhaps only his neighbours) can truly understand.

Nicolas Vonarx uses a similar 3-level theoretical model to connect on-the-ground models of illness in Haiti to that society's dominant political regimes and ideologies. Vonarx begins with a fine-grained ethnography of local talk about jealousy and envy, help-seeking activities and healing rituals. Based on years of indepth fieldwork, he describes how getting a job or having a house are enough to set off waves of pathogenic hatred in the individual's social network. Even a small upward social climb can make one vulnerable to a 'sent sickness'. Vonarx then uses a double optic for his analysis. Looking inwards into the scene of intensive fieldwork, he discerns a particular cultural logic, circumscribed in place and time and intimately connected to the experience of illness and healing. Looking outwards, he connects this discourse to processes of domination that operate in concentric circles, from the village or urban neighbourhood to the nationstate, the Caribbean region, and the global capitalist system. Each level is peripheral to, and exploited by, the next. Over the years, this structure of domination has created for most Haitians a social environment of insufficient resources and blocked opportunities. This environment-the immediate circumstances of people's lives-is the mediating factor between local experiences (and idioms) of pathogenic resentment and the large-scale fields of power. In Vonarx's closely-argued paper, an experience- near account of the cultural logic of illness becomes an acute barometer of the penetration of individual lives by national and global powers.

William Dressler takes up fundamentally the same issues but using a different theoretical model. Instead of the dichotomous choice between power and culture (and between political economy and semiotics as core research directions), Dressler discusses the dialectic of structure and agency. Instead of searching for a midrange concept to mediate the dichotomy, he insists that all social life occurs precisely at the meeting-point between external constraining forces and the creative, strategising activities of particular people. Dressler avoids heroic individualism and psychological reductionism because agency, by definition, emerges from collective discourses and the opportunities presented by a particular setting. Pursuing their own interests, people continually encounter their social world pushing back at them. The real constraints that they face close off some options and open up others, and people consequently re-think their commitments and recalibrate their practical activities.

Practice theory and similar models of structure and agency have enormous appeal in contemporary social theory because they acknowledge both the structures of domination that set limits on people's choices and the everyday practices by which people reproduce, transform or resist those structures. In his paper, Dressler applies this model to people's experience of the racial hierarchy in three societies originally founded on plantation slavery: Brazil, Puerto Rico and the southern United States. The most poisonous quality of racism in such settings is its ability to distort the individual's selfimage. From the standpoint of practice theory, the symbolic violence operates in several ways. Firstly, racist ideology justifies certain patterns of social life-from the operation of institutions such as schools to the details of face-to-face interaction-that disfavour entire classes of people. Secondly, it supports the existing class structure and the interests of those who already hold dis- 
proportionate power and wealth. Third, it naturalizes a particular value hierarchy as universal, unquestionable and indissolubly linked to skin colour and ancestry. Consequently, even people who suffer permanent dishonour in racist societies have difficulty in thinking outside of the dominant symbolic system or blunting its effects on their self-image.

Dressler operationalizes the above model by borrowing from cognitive anthropology as well as sociological studies of status. He describes people of African descent in Brazil, Puerto Rico and the southern US who try to implement dominant cultural schemata in their own lives, but who are frustrated in this aim by the dominant racial hierarchy. The self-image they desire is continually disconfirmed, and their longed-for lifestyle remains unattainable. Dressler measures the concrete consequence of failure through increased rates of hypertension, a medical disorder with considerable morbidity and mortality. In his model, the social production of hypertension turns fundamentally on the legitimacy of local categories. People accept the dominant categorical frameworks that assign worth and esteem, only to suffer when their plans for social advancement and positive selfregard are stymied. His approach shows how to read the effects of symbolic violence through people's intentions, meanings and short-term action on the ground.

Massé and Dressler offer the two most fully theoretically realised projects in this collection. The remaining articles illuminate specific debates about the uses and abuses of the notion of culture in medical anthropology. Donna Goldstein allies herself squarely with the structural violence approach. Her article examines how access to life-saving HIV/AIDS anti-retroviral drugs in middle-income countries (Argentina and Mexico) is blocked by the reigning neoliberal economic order that valorizes private profit above all else. She studies techniques of governance at the global scale: a congeries of capitalist institutions, regulatory law, nationalist logics and the trans-national flows of money, ex- perts and pharmaceuticals. Her approach seems to have no room and no need for 'culture' in the senses developed above, namely the local logics and distinctive idioms with which people seek out, use and reflect upon anti-retroviral medication.

Goldstein's interest in moral decision-making, however, makes it impossible for her to dismiss cultural meaning. In fact, she takes quite seriously the point of view of actors embedded in their social world, and she documents how they invoke as well as manipulate the discourses that surround them. The actors, in her case, are embassy officials, businesspeople, lobbyists for the Pharmaceutical Research and Manufacturers of America (PhRMA) and journalists. To be sure, they are cosmopolitans, not villagers, and they control enormous social, economic and symbolic capital. Moreover, Goldstein is unsympathetic to their viewpoint. She explicitly adopts the perspective of those who suffer in the global order because of the disproportionate power wielded by this class. She thus shifts the site of fieldwork away from locally-bounded scenes of action and towards globally-scaled networks. Her analysis turns away from fundamental sympathy with actors' perspective and towards critique. Her task is not to interpret cultural beliefs but instead to expose ideology: the self-interested worldviews that facilitate domination but disguise their effects.

Nonetheless, Goldstein's treatment of neoliberalism resembles an ethnographer's analysis of a core symbol. She investigates its lineages, its mobility across different social boundaries, its capacity to orchestrate social action and to affect individual decision-making. But unlike earlier symbolic anthropologists, Goldstein adopts the hermeneutics of suspicion, not of faith, towards neo-liberalism. Paul Ricoeur described the hermeneutics of suspicion as the approach that disputes and doubts the object of interpretation. It aims to demystify a given text or statement, not to decode or enrich its meanings. In particular, it reads cultural discourses as symptoms of domination. The belief 
in the absolute right to profit facilitates a particular structure of material power, and Goldstein interprets this belief in order to find out whose interests it supports and how people invoke it in struggles over access to needed resources. Goldstein thus does not abandon the interpretation of cultural meaning and core symbols, but reconfigures it for new social contexts and political commitments.

If Goldstein gestures towards a new and powerful type of cultural analysis, Catherine Benoit harshly criticizes the misuse of notions of culture in contemporary health policy. Illustrating the proverb that a little learning is a dangerous thing, the Haitian government and the non-governmental organizations working in that country have long considered 'cultural risk factors' in their policies to prevent and treat HIV / AIDS diseases. Unfortunately, they endorse an essentialist view of culture as a set of propositions and frameworks that wholly determines people's lives and health-care decisions. As understood by policy-makers, culture encases people inside rigid systems of belief and prevents them from absorbing new knowledge. This model of culture ignores people's strategic action: how they frame a situation according to locally relevant categories in order to pursue other projects, uphold their preferred self-image or guard against dangers in their social environment. Moreover, such a 'culturalist' approach completely elides the dynamics of domination, including the relationship between social scientists and the intended beneficiaries of their intervention. Regarding Haitians through this analytic lens renders them unequal participants in our moral world and our rationality.

Not surprisingly, the resulting health policy will have disastrous results. Programmes to train Vodoun specialists to identify symptoms of HIV infections and refer patients to biomedical care have largely failed because policy makers remain ignorant of the actual social context and practical dimensions of both Haitian religious life and the help-seeking activities of people with HIV/AIDS. Benoit's article exposes culturalism of the worst sort-the politicallyinterested and one-sided emphasis on disembodied components of belief. If anthropology is partly to blame for such a misguided project, we must get our analytic house in order. Cultural signs and models-local knowledge, idioms of distress etc.-are flexible aspects of people's practical action. They are deeply connected to the axes of power under which everyone lives, whether those connections are visible on the surface, intentionally hidden for ideological reasons or simply submerged by the demands of immediate survival.

Taken as a whole, these articles exemplify a more honest and powerful analysis of culture and power within medical anthropology. Cultural forms and practices do more than provide a blueprint for living within bounded locales. At the same time, oppressive political and economic forces do not erase local judgements of value and frameworks of meaning. The anthropologist's task at present is not to champion the one level at the expense of the other. Our task is instead to find the mediations and the moments of mutual influence that crystallize how the two levels jointly produce sickness and the social context of treatment. This special issue supplies a promising point of departure for the task at hand.

Paul Brodwin is Professor of Anthropology at the University of Wisconsin-Milwaukee. His email address isbrodwin@uwm.edu.

\section{References}

Ortner, S. 1984. 'Theory in Anthropology Since the Sixties', Comparative Studies in Society and History 26 (1): 126-166.

Ortner, S. 1999. The Fate of "Culture": Geertz and Beyond, Berkeley: University of California Press. 